\title{
Investigation of HZETRN 2010 as a Tool for Single Event Effect Qualification of Avionics Systems - Part II
}

\author{
Kristina Rojdev ${ }^{1}$, Steve Koontz ${ }^{2}$ and Brandon Reddell ${ }^{3}$ \\ NASA Johnson Space Center, Houston, TX, 77058 \\ William Atwell ${ }^{4}$ \\ Retired Boeing Technical Fellow, Houston, TX, 77058 \\ and \\ Paul Boeder ${ }^{5}$ \\ Boeing Research and Technology, Houston, TX, 77058
}

\begin{abstract}
An accurate prediction of spacecraft avionics single event effect (SEE) radiation susceptibility is key to ensuring a safe and reliable vehicle. This is particularly important for long-duration deep space missions for human exploration where there is little or no chance for a quick emergency return to Earth. Monte Carlo nuclear reaction and transport codes such as FLUKA ${ }^{12}$ can be used to generate very accurate models of the expected in-flight radiation environment for SEE analyses. A major downside to using a Monte Carlo-based code is that the run times can be very long (on the order of days). A more popular choice for $\mathrm{SEE}^{1}$ calculations is the CREME96 ${ }^{3}$ deterministic code, which offers significantly shorter run times (on the order of seconds). However, CREME96, though fast and easy to use, has not been updated in several years and underestimates secondary particle shower effects in spacecraft structural shielding mass. Another modeling option to consider is the deterministic code HZETRN $2010^{4}$, which includes updates to address secondary particle shower effects more accurately. This paper builds on previous work by Rojdev, et al. ${ }^{5}$ to compare the use of HZETRN 2010 against CREME96 as a tool to verify spacecraft avionics system reliability in a space flight SEE environment. This paper will discuss modifications made to HZETRN 2010 to improve its performance for calculating SEE rates and compare results with both in-flight SEE rates and other calculation methods.
\end{abstract}

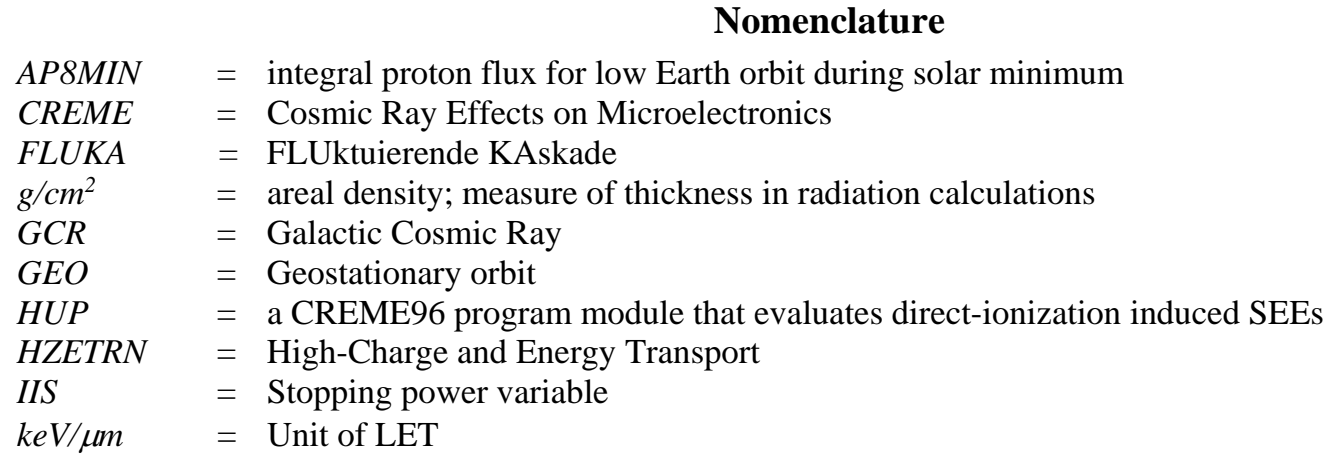

\footnotetext{
${ }^{1}$ Aerospace Engineer, Systems Engineering \& Test Branch, 2101 NASA Parkway/MC:EA351, AIAA Member.

2 International Space Station System Manager for Space Environments, 2101 NASA Parkway/MC:ES4, AIAA Member.

${ }^{3}$ Avionics Systems Division, 2101 NASA Parkway/MC:EV5.

${ }^{4}$ Retired, 16623 Park Green Way, AIAA Associate Fellow.

${ }^{5}$ Aerospace Engineer, Space Environments, 13100 Space Center Blvd./HB3-20.
} 


$\begin{array}{ll}\mathrm{km} & =\text { kilometers } \\ \mathrm{LEO} & =\text { Low Earth Orbit } \\ \mathrm{LET} & =\text { Linear Energy Transfer } \\ \mathrm{MeV}-\mathrm{cm}^{2} / g & =\text { Unit of LET normalized for a silicon sensitive volume } \\ \mathrm{SEE} & =\text { Single Event Effect } \\ \mathrm{SEU} & =\text { Single Event Upset } \\ \mathrm{Z} & =\text { Atomic Number }\end{array}$

\section{Introduction}

An accurate prediction of spacecraft avionics single event effect (SEE) radiation susceptibility is key to ensuring a safe and reliable vehicle. This is particularly important for long-duration deep space missions for human exploration where there is little or no chance for a quick emergency return to Earth. Monte Carlo nuclear reaction and transport codes such as FLUKA ${ }^{12}$ can be used to generate very accurate models of the expected in-flight radiation environment for SEE analyses. A major downside to using a Monte Carlo based code, though, is that the run times can be very long (on the order of days).

A more popular choice for SEE calculations is the CREME96 ${ }^{3}$ deterministic code which offers significantly shorter run times (on the order of seconds). However, CREME96, though fast and easy to use, has not been updated in several years and underestimates secondary particle shower effects in spacecraft structural shielding mass. Another modeling option which we investigate here is the deterministic code HZETRN 2010 4 . HZETRN was developed primarily to support human space flight radiological health requirements, but it should also be possible to also use HZETRN for avionics SEE analyses. One advantage HZETRN 2010 has over CREME96 is that it includes a more accurate representation of secondary particle shower products.

In a previous paper ${ }^{5}$, we showed that the LET spectra generated by HZETRN 2010 are limited to a maximum LET value of 11,596 MeV-cm²/g, reducing the utility of HZETRN 2010 as a tool for calculating SEU rates. To eliminate this limitation, a relatively minor change was made to the HZETRN 2010 source code to allow the calculated LET spectra output by HZETRN 2010 to be extended to higher LET values.

In the following paper, LET spectra calculations produced with CREME96 and a modified HZETRN 2010 version are compared at different aluminum shielding mass thicknesses for both the interplanetary GCR environment and the International Space Station low-Earth orbit environment. Finally, space flight SEU rates are compared with rate predictions made using both deterministic codes.

\section{Methods}

The CREME96 GCR model was used to generate both the HZETRN and CREME96 LET spectra data for this assessment. This was done to ensure that transport calculation results for the same input environment would be compared between the two codes. Solar minimum conditions were selected, which lead to higher intensity GCR exposure due to the inverse relationship between solar activity and GCR activity. An altitude of $362.5 \mathrm{~km}$ and orbit inclination of $51.6^{\circ}$ was specified for the LEO environment comparison. AP8MIN trapped protons were also included for the LEO environment definition. For the HZETRN calculations, the CREME96 generated spectra were interpolated against the HZETRN 2010 energy grid. The LEO $(362.5 \mathrm{~km})$ and free space particle environments are plotted in Figures 1 and 2, respectively. Only a subset of the heavy ion elements present in the environment models are plotted to avoid cluttering the two figures.

American Institute of Aeronautics and Astronautics 


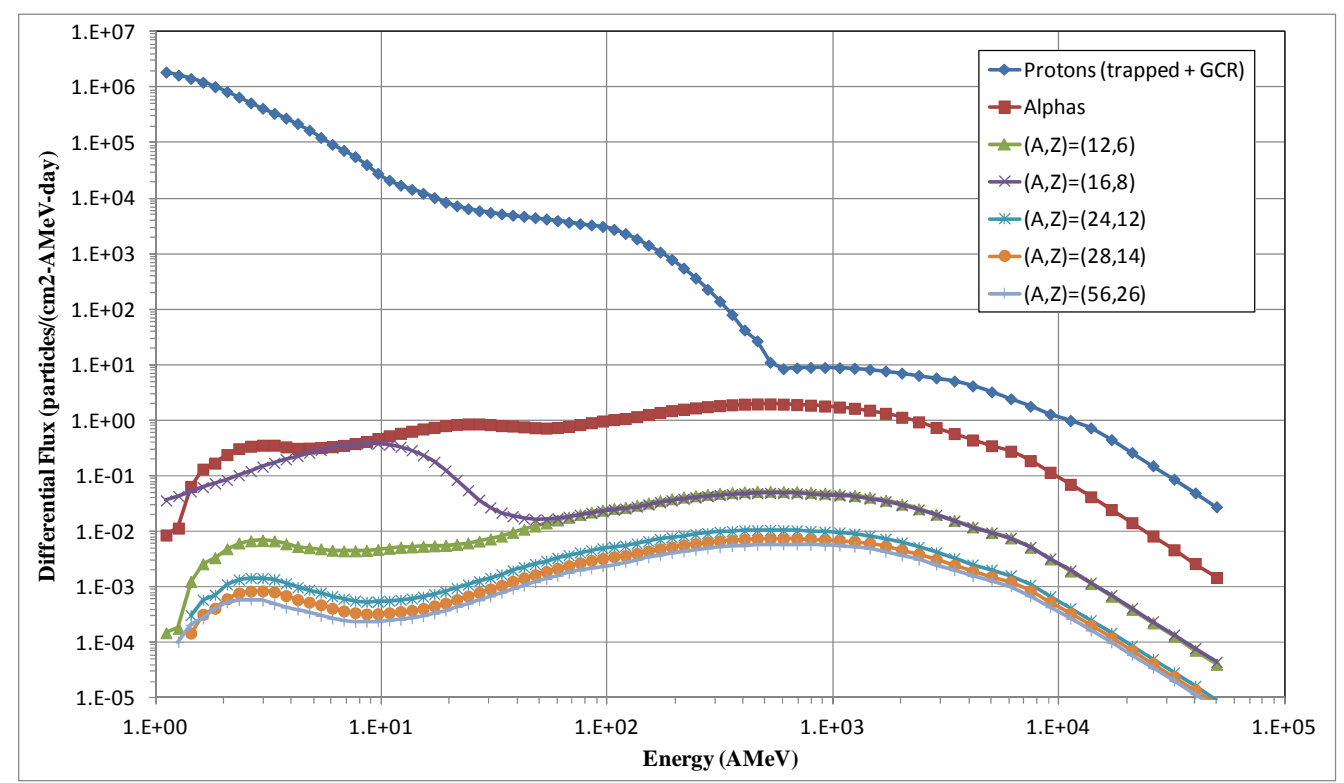

Figure 1. CREME96 solar minimum differential flux environment at $362.5 \mathrm{~km}$ and $51.6^{\circ}$ inclination.

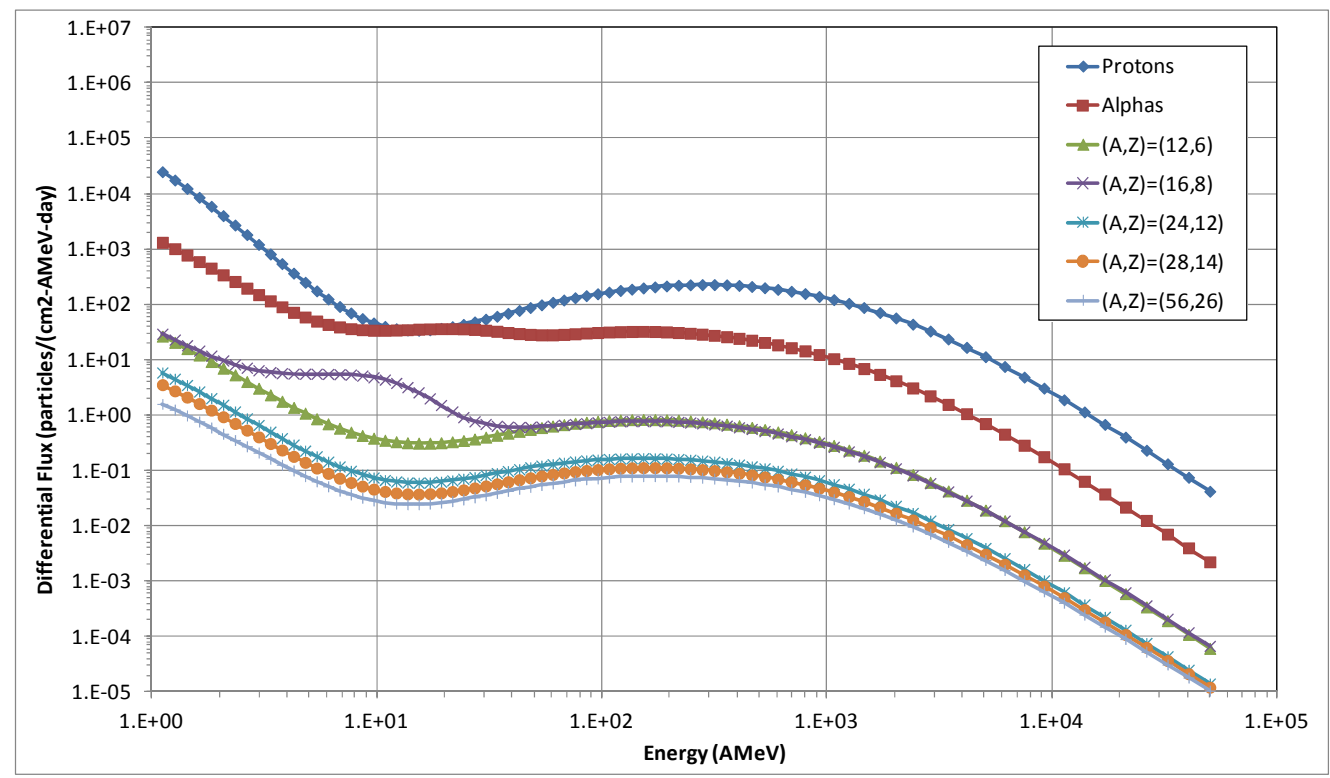

Figure 2. CREME96 solar minimum GCR differential flux environment for GEO and free space.

As discussed in a previous paper ${ }^{5}$, the current version of HZETRN 2010 only includes elements out to Nickel (Z $=28$ ). Extending the element range to higher $Z$ particles would involve integrating a new environment model into HZETRN 2010 and was deemed out of scope for this study. The standard version of HZETRN 2010 also only outputs a maximum LET of 11,692 MeV-cm²/g for the GCR environment as compared to 30,364 MeV-cm²/g for CREME96 (for max $Z=28$ ). Extending the output LET range maximum in HZETRN 2010 can be accomplished by increasing the stopping power variable (IIS) in the HZETRN 2010 subroutines LETDIF and LETINT for calculating LET. For this study, IIS was increased from the default value of 700 to 780, which increases the maximum output LET to 7352 $\mathrm{keV} / \mu \mathrm{m}$, which is equivalent to $31,552 \mathrm{MeV}-\mathrm{cm}^{2} / \mathrm{g}$ in silicon. 31,552 $\mathrm{MeV}-\mathrm{cm}^{2} / \mathrm{g}$ is very close to the maximum LET of 30,364 MeV-cm²/g output by CREME96 for a maximum $\mathrm{Z}=28$.

For the particle transport computational runs in the modified HZETRN 2010 and CREME96, spacecraft shielding was simulated using uniform aluminum shield layers of the following thickness: 0.1, 0.5, 1.0, 5.0, 10.0, 20.0 and 50.0 $\mathrm{g} / \mathrm{cm}^{2}$. A silicon detector behind the aluminum shield layer was used to simulate the sensitive volume of an electronic

American Institute of Aeronautics and Astronautics 
device. Integral LET spectra were output from each transport code. These LET spectra were then compared between the two transport codes. Further analysis was then completed with CREME96 using the LET spectra from both codes to generate SEE rates for comparison. Results for $0.1,5.0$, and $50.0 \mathrm{~g} / \mathrm{cm}^{2}$ are presented herein.

\section{Results}

Integral flux LET spectra for shielding values of $0.1,5.0$, and $50.0 \mathrm{~g} / \mathrm{cm}^{2}$ generated from the modified HZETRN 2010 and CREME96 with maximum Z $=28$ are compared in Figure 3 through 5 for the LEO orbit and Figure 6 through 8 for the GEO GCR environment.

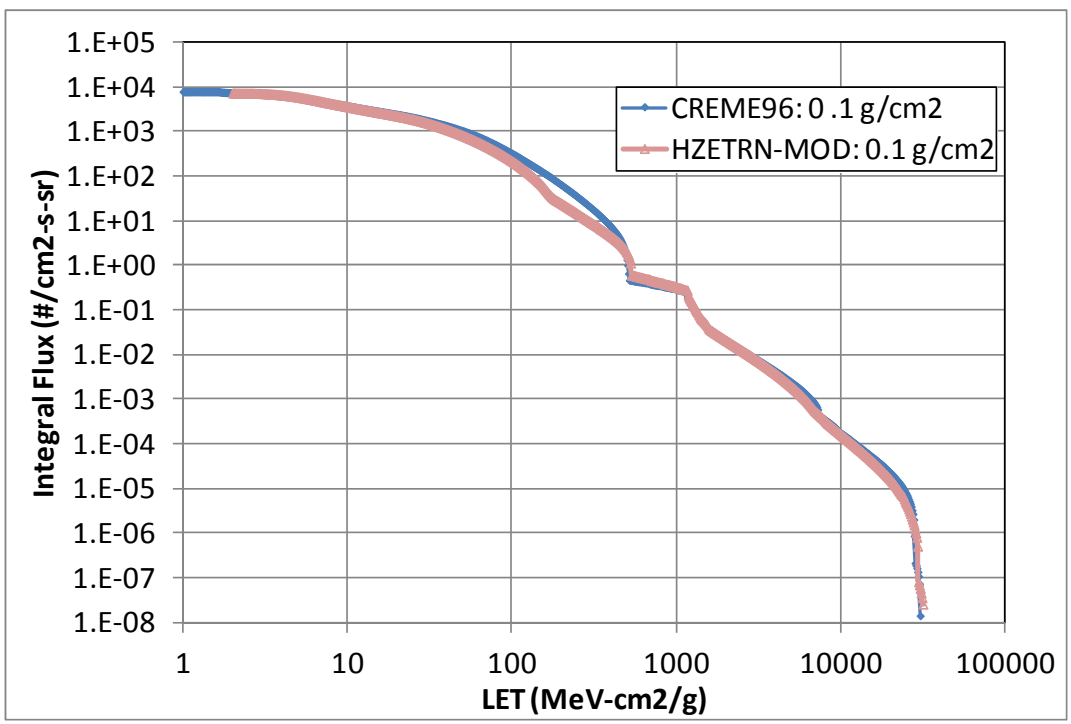

Figure 3. CREME vs. modified HZETRN LEO Integral flux at $0.1 \mathrm{~g} / \mathrm{cm}^{2}$ thickness.

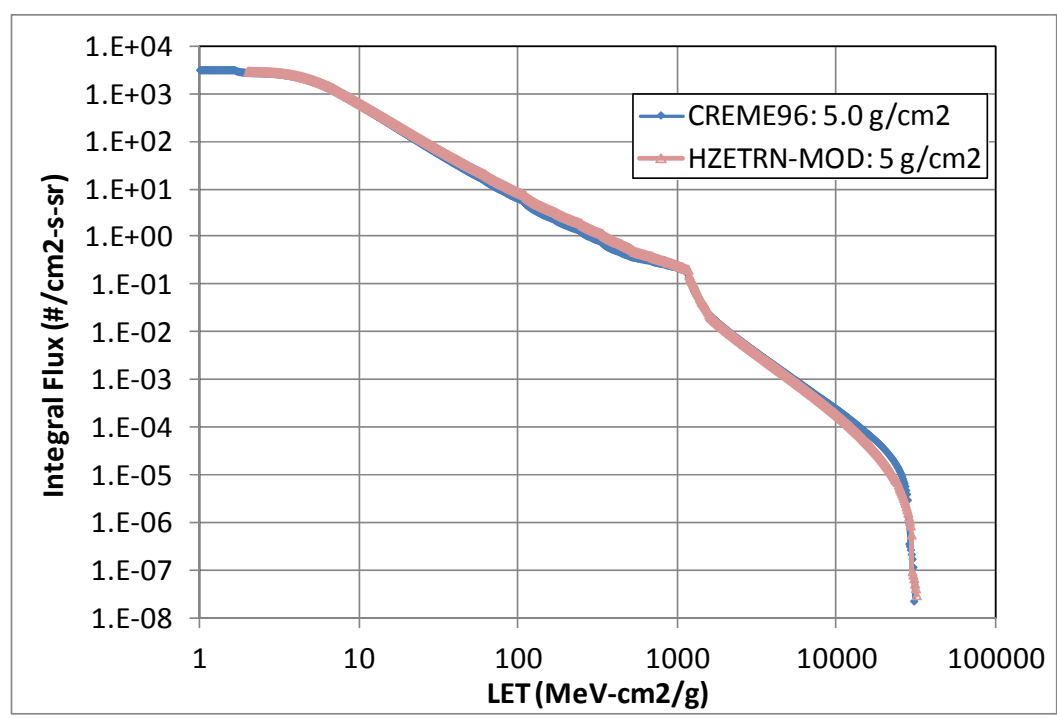

Figure 4. CREME vs. modified HZETRN LEO Integral flux at $5.0 \mathrm{~g} / \mathrm{cm}^{2}$ thickness. 


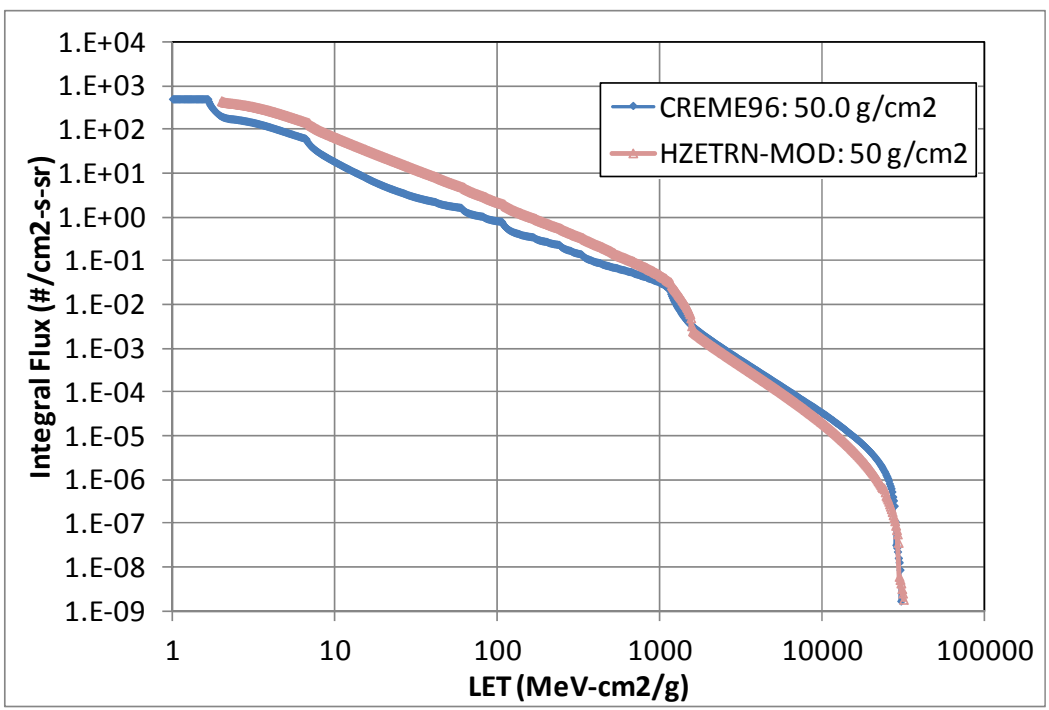

Figure 5. CREME vs. modified HZETRN LEO Integral flux at $50.0 \mathrm{~g} / \mathrm{cm}^{2}$ thickness.

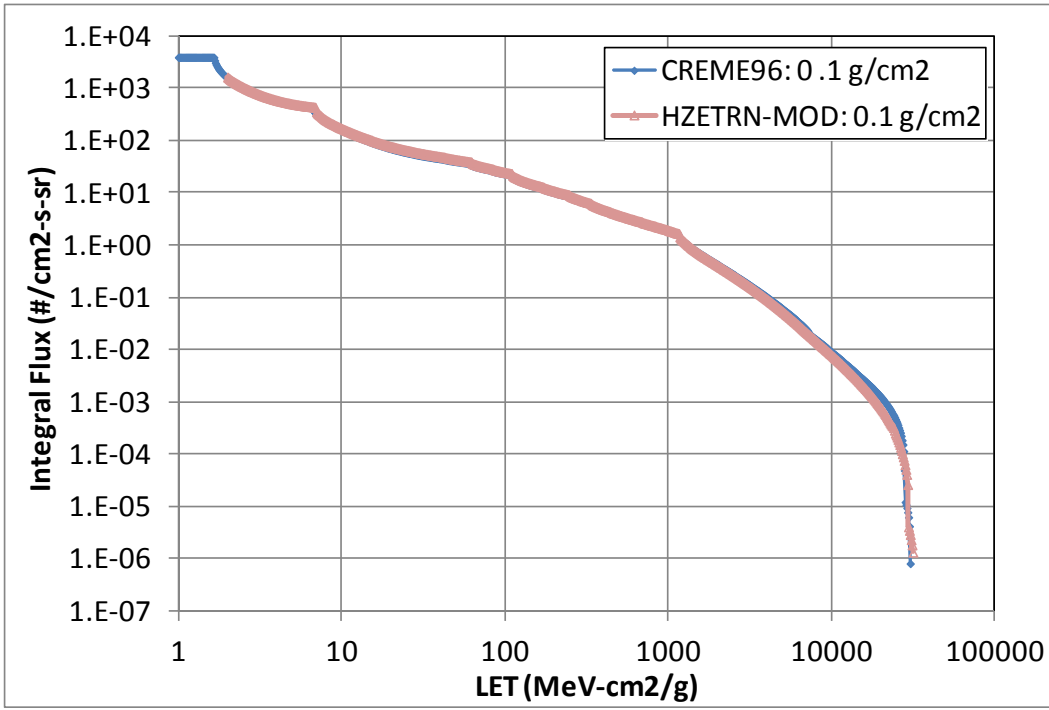

Figure 6. CREME vs. modified HZETRN GEO Integral flux at $0.1 \mathrm{~g} / \mathrm{cm}^{2}$ thickness. 


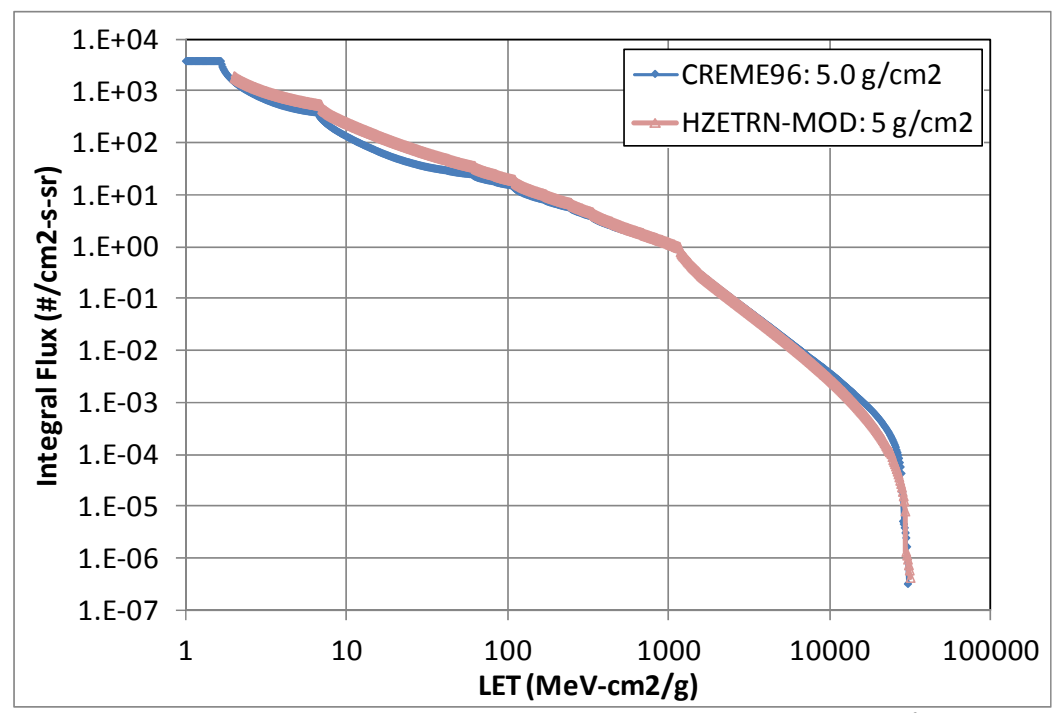

Figure 7. CREME vs. modified HZETRN GEO Integral flux at $5.0 \mathrm{~g} / \mathrm{cm}^{2}$ thickness.

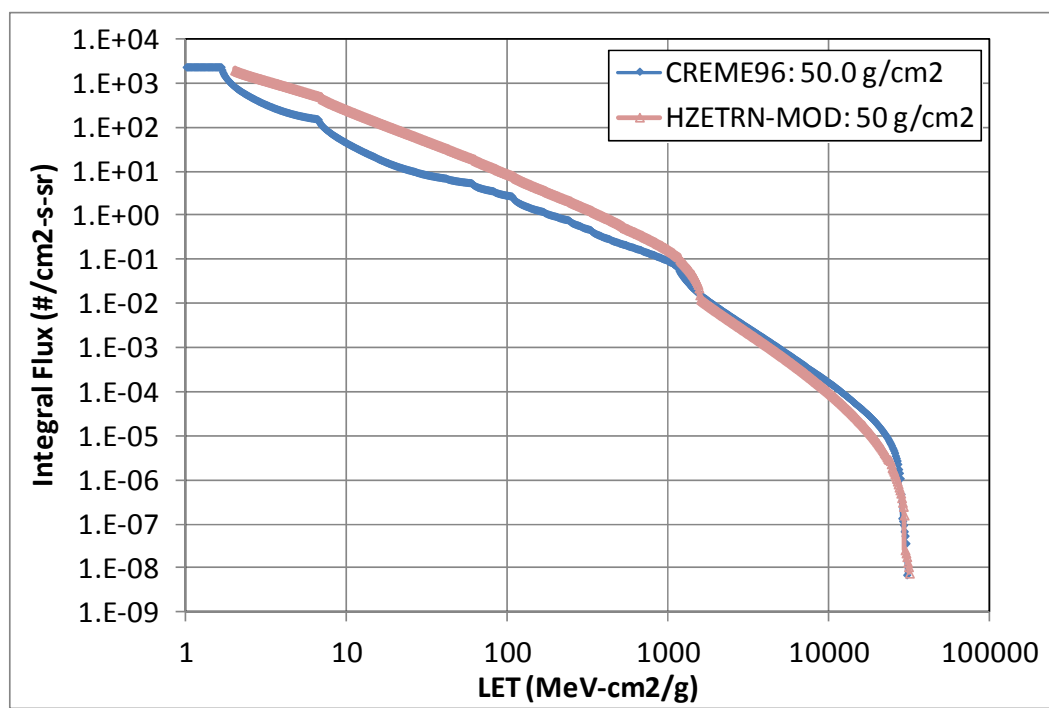

Figure 8. CREME vs. modified HZETRN GEO Integral flux at $50.0 \mathrm{~g} / \mathrm{cm}^{2}$ thickness.

Radiation characterization parameters for several devices flown either on ISS, GEO, and deep space missions are given in 
Table $1^{6}$. The table shows SEE sensitive volume dimensions and Weibull fit parameters for each device. 
Table 1. Device Parameters.

\begin{tabular}{|c|c|c|c|c|c|c|}
\hline Device & Env & $\begin{array}{c}\text { CREME96 RPP } \\
\text { x,y,z }(\mu \mathrm{m})\end{array}$ & $\begin{array}{c}\text { Onset } \\
\left(\mathrm{MeV}-\mathrm{cm}^{2} / \mathrm{g}\right)\end{array}$ & $\begin{array}{c}\text { Width } \\
\left(\mathrm{MeV}-\mathrm{cm}^{2} / \mathrm{mg}\right)\end{array}$ & Exponent & $\begin{array}{c}\text { Limiting XS } \\
\left(\mu \mathbf{m}^{2}\right)\end{array}$ \\
\hline IMS1601EPI & ISS & $39.5,39.5,5.92$ & 2750 & 140 & 0.95 & 1560 \\
\hline ISS SMJ416400 4Mx4 DRAM & ISS & $1.05,1.05,2.1$ & 420 & 0.8 & 1.7 & 1.1 \\
\hline ISS KM44S32030T 128Mbit SDRAM & ISS & $2.42,2.42,0.24$ & 13000 & 30 & 1 & 5.859 \\
\hline ISS KM44S32030T 128Mbit SDRAM & ISS & $1.25,1.25,0.125$ & 14000 & 30 & 1 & 1.563 \\
\hline ISS KM44S32030T 128Mbit SDRAM & ISS & $0.43,0.43,0.043$ & 1950 & 30 & 1.9 & 0.186 \\
\hline V4 XQR4VFX60 - BRAM & ISS & $1.87,1.87,3.74$ & 200 & 70 & 0.724 & 3.5 \\
\hline V4 XQR4VFX60 - Config. Memory & ISS & $5.1,5.1,10.2$ & 500 & 400 & 0.985 & 26 \\
\hline V5 LX330T - Config. Memory & ISS & 3.36, 3.36, 6.72 & 500 & 30 & 1.5 & 11.3 \\
\hline Thuraya DSP Mega gate ASIC & GEO & $2.5,2.5,1.76$ & 2700 & 20.6 & 1.2 & 6.3 \\
\hline Mercury Messenger ASIC & GEO & $2,2,2$ & 300 & 60 & 6 & 4 \\
\hline Cassini OKI Solid State Recorder & GEO & $6.32,6.32,6.32$ & 500 & 32 & 3 & 40 \\
\hline SOHO SMJ44100 4Mx1 & GEO & $7.07,7.07,2$ & 700 & 15 & 2.7 & 50 \\
\hline SOHO MHS CP65656EV 32kx8 SRAM & GEO & $7.75,7.75,2$ & 1900 & 17 & 1.2 & 60 \\
\hline ETS-V PD4464D-20 64k SRAM & GEO & $19,19,10$ & 500 & 15 & 2.9 & 375 \\
\hline
\end{tabular}

SEE rates were calculated for these devices for three different LET spectra variations shown in Table 2 using the CREME96 HUP heavy ion SEE rate calculator.

Table 2. LET Spectra Variations

\begin{tabular}{|c|c|c|c|}
\hline $\begin{array}{c}\text { Code } \\
\text { Max Z }\end{array}$ & $\begin{array}{c}\text { Max LET } \\
\left(\mathbf{M e V}-\mathbf{~ c m}^{2} / \mathbf{g}\right)\end{array}$ & $\begin{array}{c}\text { Min LET } \\
\left(\mathbf{M e V}-\mathbf{~ c m}^{2} / \mathbf{g}\right)\end{array}$ \\
\hline Modified HZETRN & 28 & 31,552 & 1 \\
\hline CREME96 & 28 & 30,364 & 1 \\
\hline CREME96 & 92 & 101,000 & 1 \\
\hline
\end{tabular}

To calculate SEE rates with CREME96 HUP using the HZETRN 2010 LET spectra, the spectra were first modified to conform to the CREME96 LET energy grid and then imported into the CREME96 website. SEE rates for shielding values for $0.1,5.0$, and $50.0 \mathrm{~g} / \mathrm{cm}^{2}$ are given in Table 5 for LEO environment devices and Table 6 - Table 8 for GEO and free space environment devices. All shielding depths are aluminum equivalent. Note that for the $50 \mathrm{~g} / \mathrm{cm}^{2}$ thickness (Table 5 and Table 8) there is no data for CREME96 (Z=92) because CREME96 was unable to calculate SEE rates for this shielding thickness value. Rates for devices without the number of bits listed may be assumed to be device rates. 
Table 3. SEE Rate for LEO Devices at $0.1 \mathrm{~g} / \mathrm{cm}^{2}$

\begin{tabular}{|l|c|c|c|}
\hline \multicolumn{1}{|c|}{ Depth = 0.1 g/cm } & \multicolumn{3}{c|}{ SEE/bit-day } \\
\hline \multicolumn{1}{|c|}{ LEO Environment Devices } & $\begin{array}{c}\text { HZETRN } \\
\text { Max Z=28 }\end{array}$ & $\begin{array}{c}\text { CREME96 } \\
\text { Max Z=28 }\end{array}$ & $\begin{array}{c}\text { CREME96 } \\
\text { Max Z=92 }\end{array}$ \\
\hline IMS1601EPI & $1.79 \mathrm{E}-06$ & $1.76 \mathrm{E}-06$ & $1.77 \mathrm{E}-06$ \\
\hline ISS TMS44400 1Mx4 DRAM & $9.45 \mathrm{E}-09$ & $1.14 \mathrm{E}-08$ & $1.15 \mathrm{E}-08$ \\
\hline ISS SMJ416400 4Mx4 DRAM & $1.48 \mathrm{E}-07$ & $1.31 \mathrm{E}-07$ & $1.31 \mathrm{E}-07$ \\
\hline ISS KM44S32030T 128Mbit SDRAM & $1.27 \mathrm{E}-09$ & $1.33 \mathrm{E}-09$ & $1.34 \mathrm{E}-09$ \\
\hline ISS KM44S32030T 128Mbit SDRAM & $2.77 \mathrm{E}-10$ & $2.97 \mathrm{E}-10$ & $2.98 \mathrm{E}-10$ \\
\hline ISS KM44S32030T 128Mbit SDRAM & $3.38 \mathrm{E}-10$ & $4.09 \mathrm{E}-10$ & $4.10 \mathrm{E}-10$ \\
\hline V4 XQR4VFX60 - BRAM & $2.86 \mathrm{E}-07$ & $4.61 \mathrm{E}-07$ & $4.67 \mathrm{E}-07$ \\
\hline V4 XQR4VFX60 - Config. Memory & $1.23 \mathrm{E}-08$ & $1.10 \mathrm{E}-08$ & $1.10 \mathrm{E}-08$ \\
\hline V5 LX330T - Config. Memory & $9.29 \mathrm{E}-09$ & $8.82 \mathrm{E}-09$ & $8.85 \mathrm{E}-09$ \\
\hline
\end{tabular}

Table 4. SEE Rate for LEO Devices at $5.0 \mathrm{~g} / \mathrm{cm}^{2}$

\begin{tabular}{|l|c|c|c|}
\hline \multicolumn{1}{|c|}{ Depth $=\mathbf{5 . 0}$ g/cm } & \multicolumn{3}{c|}{ SEE/bit-day } \\
\hline \multicolumn{1}{|c|}{ LEO Environment Devices } & $\begin{array}{c}\text { HZETRN } \\
\text { Max Z=28 }\end{array}$ & $\begin{array}{c}\text { CREME96 } \\
\text { Max Z=28 }\end{array}$ & $\begin{array}{c}\text { CREME96 } \\
\text { Max Z=92 }\end{array}$ \\
\hline IMS1601EPI & $1.06 \mathrm{E}-06$ & $9.24 \mathrm{E}-07$ & $9.27 \mathrm{E}-07$ \\
\hline ISS TMS44400 1Mx4 DRAM & $8.77 \mathrm{E}-09$ & $1.07 \mathrm{E}-08$ & $1.08 \mathrm{E}-08$ \\
\hline ISS SMJ416400 4Mx4 DRAM & $1.04 \mathrm{E}-07$ & $9.02 \mathrm{E}-08$ & $9.04 \mathrm{E}-08$ \\
\hline ISS KM44S32030T 128Mbit SDRAM & $8.15 \mathrm{E}-10$ & $8.73 \mathrm{E}-10$ & $8.79 \mathrm{E}-10$ \\
\hline ISS KM44S32030T 128Mbit SDRAM & $1.76 \mathrm{E}-10$ & $1.94 \mathrm{E}-10$ & $1.95 \mathrm{E}-10$ \\
\hline ISS KM44S32030T 128Mbit SDRAM & $1.75 \mathrm{E}-10$ & $1.55 \mathrm{E}-10$ & $1.55 \mathrm{E}-10$ \\
\hline V4 XQR4VFX60 - BRAM & $8.37 \mathrm{E}-08$ & $6.30 \mathrm{E}-08$ & $6.33 \mathrm{E}-08$ \\
\hline V4 XQR4VFX60 - Config. Memory & $8.65 \mathrm{E}-09$ & $7.67 \mathrm{E}-09$ & $7.70 \mathrm{E}-09$ \\
\hline V5 LX330T - Config. Memory & $6.33 \mathrm{E}-09$ & $5.99 \mathrm{E}-09$ & $6.01 \mathrm{E}-09$ \\
\hline
\end{tabular}

Table 5. SEE Rate for LEO Devices at $50.0 \mathrm{~g} / \mathrm{cm}^{2}$

\begin{tabular}{|l|c|c|}
\hline \multicolumn{1}{|c|}{ Depth = 50.0 g/cm } & \multicolumn{2}{c|}{ SEE/bit-day } \\
\hline \multicolumn{1}{|c|}{ LEO Environment Devices } & $\begin{array}{c}\text { HZETRN } \\
\text { Max Z=28 }\end{array}$ & $\begin{array}{c}\text { CREME96 } \\
\text { Max Z=28 }\end{array}$ \\
\hline IMS1601EPI & $2.15 \mathrm{E}-07$ & $1.39 \mathrm{E}-07$ \\
\hline ISS TMS44400 1Mx4 DRAM & $9.83 \mathrm{E}-10$ & $1.51 \mathrm{E}-09$ \\
\hline ISS SMJ416400 4Mx4 DRAM & $2.05 \mathrm{E}-08$ & $1.30 \mathrm{E}-08$ \\
\hline ISS KM44S32030T 128Mbit SDRAM & $1.13 \mathrm{E}-10$ & $1.22 \mathrm{E}-10$ \\
\hline ISS KM44S32030T 128Mbit SDRAM & $2.30 \mathrm{E}-11$ & $2.73 \mathrm{E}-11$ \\
\hline ISS KM44S32030T 128Mbit SDRAM & $3.47 \mathrm{E}-11$ & $2.31 \mathrm{E}-11$ \\
\hline V4 XQR4VFX60 - BRAM & $2.15 \mathrm{E}-08$ & $1.05 \mathrm{E}-08$ \\
\hline V4 XQR4VFX60 - Config. Memory & $1.65 \mathrm{E}-09$ & $1.10 \mathrm{E}-09$ \\
\hline V5 LX330T - Config. Memory & $1.09 \mathrm{E}-09$ & $8.49 \mathrm{E}-10$ \\
\hline
\end{tabular}


Table 6. SEE Rate for GEO Devices at $0.1 \mathrm{~g} / \mathrm{cm}^{2}$

\begin{tabular}{|l|c|c|c|}
\hline \multicolumn{1}{|c|}{ Depth $=\mathbf{0 . 1} \mathbf{~ g / \mathbf { c m } ^ { 2 }}$} & \multicolumn{3}{c|}{ SEE/bit-day } \\
\hline \multicolumn{1}{|c|}{ GEO Environment Devices } & $\begin{array}{c}\text { HZETRN } \\
\text { Max Z=28 }\end{array}$ & $\begin{array}{c}\text { CREME96 } \\
\text { Max Z=28 }\end{array}$ & $\begin{array}{c}\text { CREME96 } \\
\text { Max Z=92 }\end{array}$ \\
\hline Thuraya DSP Mega gate ASIC & $1.02 \mathrm{E}-07$ & $1.13 \mathrm{E}-07$ & $1.13 \mathrm{E}-07$ \\
\hline Mercury Messenger ASIC & $2.37 \mathrm{E}-11$ & $3.56 \mathrm{E}-11$ & $3.65 \mathrm{E}-11$ \\
\hline Cassini OKI Solid State Recorder & $4.94 \mathrm{E}-08$ & $5.96 \mathrm{E}-08$ & $5.99 \mathrm{E}-08$ \\
\hline SOHO SMJ44100 4Mx1 & $1.38 \mathrm{E}-06$ & $1.49 \mathrm{E}-06$ & $1.49 \mathrm{E}-06$ \\
\hline SOHO MHS CP65656EV 32kx8 SRAM & $3.44 \mathrm{E}-06$ & $3.58 \mathrm{E}-06$ & $3.58 \mathrm{E}-06$ \\
\hline ETS-V PD4464D-20 64k SRAM & $6.49 \mathrm{E}-06$ & $7.15 \mathrm{E}-06$ & $7.16 \mathrm{E}-06$ \\
\hline
\end{tabular}

Table 7. SEE Rate for GEO Devices at $5.0 \mathrm{~g} / \mathrm{cm}^{2}$

\begin{tabular}{|l|c|c|c|}
\hline \multicolumn{1}{|c|}{ Depth $=\mathbf{5 . 0} \mathbf{~ g / \mathbf { c m } ^ { 2 }}$} & \multicolumn{3}{c|}{ SEE/bit-day } \\
\hline \multicolumn{1}{|c|}{ GEO Environment Devices } & $\begin{array}{r}\text { HZETRN } \\
\text { Max Z=28 }\end{array}$ & $\begin{array}{c}\text { CREME96 } \\
\text { Max Z=28 }\end{array}$ & $\begin{array}{c}\text { CREME96 } \\
\text { Max Z=92 }\end{array}$ \\
\hline Thuraya DSP Mega gate ASIC & $3.50 \mathrm{E}-08$ & $3.93 \mathrm{E}-08$ & $3.94 \mathrm{E}-08$ \\
\hline Mercury Messenger ASIC & $7.91 \mathrm{E}-12$ & $1.40 \mathrm{E}-11$ & $1.43 \mathrm{E}-11$ \\
\hline Cassini OKI Solid State Recorder & $1.73 \mathrm{E}-08$ & $2.26 \mathrm{E}-08$ & $2.27 \mathrm{E}-08$ \\
\hline SOHO SMJ44100 4Mx1 & $5.48 \mathrm{E}-07$ & $5.82 \mathrm{E}-07$ & $5.83 \mathrm{E}-07$ \\
\hline SOHO MHS CP65656EV 32kx8 SRAM & $1.56 \mathrm{E}-06$ & $1.58 \mathrm{E}-06$ & $1.58 \mathrm{E}-06$ \\
\hline ETS-V PD4464D-20 64k SRAM & $2.40 \mathrm{E}-06$ & $2.67 \mathrm{E}-06$ & $2.67 \mathrm{E}-06$ \\
\hline
\end{tabular}

Table 8. SEE Rate for GEO Devices at $50.0 \mathrm{~g} / \mathrm{cm}^{2}$

\begin{tabular}{|l|c|c|}
\hline \multicolumn{1}{|c|}{ Depth $=\mathbf{5 0 . 0} \mathbf{~ g / \mathbf { c m } ^ { 2 }}$} & \multicolumn{2}{c|}{ SEE/bit-day } \\
\hline \multicolumn{1}{|c|}{ GEO Environment Devices } & $\begin{array}{c}\text { HZETRN } \\
\text { Max Z=28 }\end{array}$ & $\begin{array}{c}\text { CREME96 } \\
\text { Max Z=28 }\end{array}$ \\
\hline Thuraya DSP Mega gate ASIC & $1.45 \mathrm{E}-09$ & $1.94 \mathrm{E}-09$ \\
\hline Mercury Messenger ASIC & $2.26 \mathrm{E}-13$ & $5.15 \mathrm{E}-13$ \\
\hline Cassini OKI Solid State Recorder & $7.33 \mathrm{E}-10$ & $1.04 \mathrm{E}-09$ \\
\hline SOHO SMJ44100 4Mx1 & $4.25 \mathrm{E}-08$ & $3.40 \mathrm{E}-08$ \\
\hline SOHO MHS CP65656EV 32kx8 SRAM & $1.67 \mathrm{E}-07$ & $1.06 \mathrm{E}-07$ \\
\hline ETS-V PD4464D-20 64k SRAM & $1.43 \mathrm{E}-07$ & $1.42 \mathrm{E}-07$ \\
\hline
\end{tabular}

Figure 9 compares in-flight SEU rates with rates calculated using HZETRN 2010, FLUKA and CREME96 using the accompanying least squares performance metric equations. Tabulated rates for in-flight, FLUKA, CREME96 and the modified HZETRN2010 code may be found in Table 9. The modified HZETRN 2010 rate calculations are in general agreement with both the FLUKA and CREME96 SEE rate calculation results and compare favorably with inflight measurements of SEU rates. 

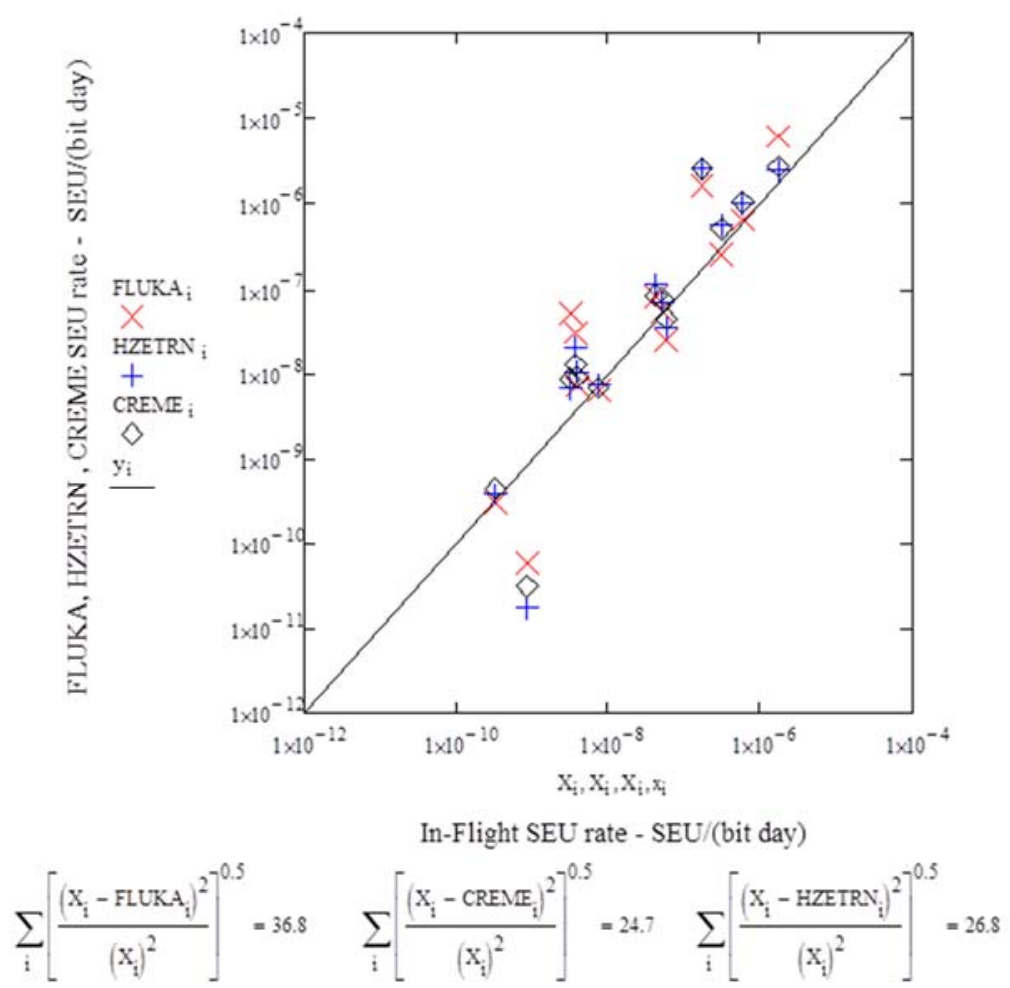

Figure 9. Comparing FLUKA, CREME, and modified HZETRN 2010 SEU rate estimates with in-flight SEU rates. 
Table 9. Flight SEE Rates Compared to HZETRN and CREME96 Based SEE Rates.

\begin{tabular}{|c|c|c|c|c|c|}
\hline Device & Env & $\begin{array}{c}\text { Median } \\
\text { Shielding Mass } \\
\text { g/cm² (3) }\end{array}$ & $\begin{array}{c}\text { In-Flight } \\
\text { SEU/bit day }\end{array}$ & $\begin{array}{c}\text { CREME96 } \\
\text { Predicted } \\
\text { SEU/bit day (1) }\end{array}$ & $\begin{array}{l}\text { HZETRN } \\
\text { Predicted } \\
\text { SEU/bit day } \\
\text { (2) }\end{array}$ \\
\hline IMS1601EPI & ISS & $34(20)$ & 3.10E-07 & 4.86E-07 & $5.46 \mathrm{E}-07$ \\
\hline ISS SMJ416400 4Mx4 DRAM & ISS & 10 & $3.20 \mathrm{E}-09$ & 8.55E-09 & $6.74 \mathrm{E}-09$ \\
\hline ISS SMJ416400 4Mx4 DRAM (4) & ISS & $40(50)$ & 3.70E-09 & 1.30E-08 & 2.05E-08 \\
\hline ISS KM44S32030T 128Mbit SDRAM & ISS & $40(20)$ & $3.30 \mathrm{E}-10$ & 4.42E-10 & $3.85 \mathrm{E}-10$ \\
\hline V4 XQR4VFX60 - BRAM & ISS & $0.8(1)$ & 4.20E-08 & $8.24 \mathrm{E}-08$ & 1.13E-07 \\
\hline V4 XQR4VFX60 - Config. Memory & ISS & $0.8(1)$ & 3.80E-09 & 9.04E-09 & $1.05 \mathrm{E}-08$ \\
\hline V5 LX330T - Config. Memory & ISS & $0.8(1)$ & 7.60E-09 & 6.95E-09 & 7.63E-09 \\
\hline Thuraya DSP Mega gate ASIC & GEO & $0.7(1)$ & 5.30E-08 & 7.55E-08 & 6.91E-08 \\
\hline Mercury Messenger ASIC & GEO & 1 & $8.60 \mathrm{E}-10$ & 3.04E-11 & $1.74 \mathrm{E}-11$ \\
\hline Cassini OKI Solid State Recorder & GEO & $3.4(1)$ & $5.80 \mathrm{E}-08$ & 4.53E-08 & $3.54 \mathrm{E}-08$ \\
\hline SOHO SMJ44100 4Mx1 & GEO & 1 & 5.90E-07 & 1.04E-06 & 9.84E-07 \\
\hline SOHO MHS CP65656EV 32kx8 SRAM & GEO & 1 & $1.70 \mathrm{E}-07$ & $2.59 \mathrm{E}-06$ & $2.56 \mathrm{E}-06$ \\
\hline ETS-V PD4464D-20 64k SRAM & GEO & $5.8(5)$ & $1.70 \mathrm{E}-06$ & 2.67E-06 & 2.40E-06 \\
\hline \multicolumn{6}{|c|}{$\begin{array}{l}\text { Table Notes: } \\
\text { 1) CREME96 Predicted (Z=92, Max LET } \sim 100 \mathrm{MeV}-\mathrm{cm} 2 / \mathrm{mg}) \\
\text { 2) HZETRN Predicted ( } \mathrm{Z}=28 \text {, Max LET } \sim 32 \mathrm{MeV}-\mathrm{cm} 2 / \mathrm{mg}) \\
\text { 3) First value is the estimated on-orbit shielding for the device. Number in parenthesis is the shielding value used to calculate } \\
\text { the CREME96 and HZETRN rates (if different from the estimated flight shielding). } \\
\text { 4) for this device shielding combination. the CREME96 prediction is for } \mathrm{Z}=28 \text {, Max LET } \sim 32 \mathrm{MeV}-\mathrm{cm} 2 / \mathrm{mg} \text {. CREME96 } \\
\text { would not calculate an SEE rate for the full } \mathrm{Z}=92 \text { spectra. } \\
\text { Median shielding mass and in-flight SEU rates taken from ref. } 1 \text {. }\end{array}$} \\
\hline
\end{tabular}

\section{Discussion}

Direct comparison of the LET spectra produced by CREME96 and the modified HZETRN 2010 (Figure 3-Figure 8) shows that the modified HZETRN 2010 code produces LET spectra similar to CREME96. As shielding thickness increases, HZETRN 2010 predicts higher fluxes in the low LET range less than $1000 \mathrm{MeV}-\mathrm{cm} 2 / \mathrm{g}$.

Comparison of CREME96 SEE rate calculation results shown in Table 6-Table 8 for GCR with maximum Z=28 with results for GCR with maximum Z=92 shows that inclusion of the higher Z GCR elements had little impact on the overall SEE rates of the devices. This was expected, given the very low flux of GCR particles with $Z>28$. Note also that all of these devices assessed have low or moderately low LET thresholds. Incorporating the high Z component of the environment is not so important for devices like these. The high $\mathrm{Z}$ elements become important for devices with higher LET thresholds and it is especially important for devices that may be susceptible to high-threshold destructive failures, such as single event latch-up and single event burnout.

Figure 9 and Table 9 show that the HZETRN 2010 SEE rate predictions are generally conservative as compared to in-flight observations. HZETRN 2010 SEE rate predictions for the devices selected are also essentially the same as CREME96 SEE rate predictions. The disparity between the predicted and observed SEE rate for the Mercury Messenger ASIC is most likely due to the presence of a Tantalum $(\mathrm{Z}=73)$ overburden layer in the device which is not accounted for in the predicted SEE rate calculations. Nonetheless, the performance of HZETRN 2010 in predicting in-flight SEU rates is comparable to FLUKA and CREME96 for the devices studied here.

What are the advantages and disadvantages of using HZETRN 2010 to model the SEE environment? The main advantage is that HZETRN2010 allows the use of any input environment model for calculating particle flux and LET

American Institute of Aeronautics and Astronautics 
spectra at depth. Therefore, you can use any environment model to determine SEE rates. HZETRN 2010 also includes a more accurate representation of secondary particle shower products.

There are two primary disadvantages to using HZETRN 2010 for SEE rate calculations. The maximum LET output by the standard version of HZETRN 2010 is $11,692 \mathrm{MeV}-\mathrm{cm}^{2} / \mathrm{g}$. The maximum LET output by the modified version of HZETRN 2010 used in this paper is 30,364 MeV-cm²/g. To make HZETRN 2010 fully acceptable for spacecraft avionics SEE rate calculations, the range of the LET output tables needs to be extended to $100,000 \mathrm{MeV}-\mathrm{cm}^{2} / \mathrm{g}$ to handle high LET threshold devices. Additional modifications to HZETRN 2010 are required in order to properly transport the heavier ion species $(\mathrm{Z}>28)$ needed to produce these higher LET values. The other disadvantage is that HZETRN 2010 does not include a SEE rate calculation module, so the user would have to find an alternate method for calculating SEE rates.

\section{Conclusion}

The results in this paper show that a modified HZETRN 2010 is a viable alternative for determining LET spectra for SEU rate calculations for devices with low to moderate LET thresholds. To make HZETRN 2010 fully acceptable for spacecraft avionics SEE rate calculations, the range of the LET output tables needs to be extended to 100,000 $\mathrm{MeV}-\mathrm{cm}^{2} / \mathrm{g}$ to handle high LET threshold devices. The HZETRN 2010 user would also be responsible for performing their own SEE rate calculations since HZETRN 2010 does not include an SEE rate calculation module.

\section{References}

1"The FLUKA Code: Developments and Challenges for High Energy and Medical Applications" T.T. Bohlen, F. Cerutti, M.P.W. Chin, A. Fasso`, A. Ferrari, P.G. Ortega, A. Mairani, P.R. Sala, G. Smirnov, and V. Vlachoudis, Nuclear Data Sheets 120, 211-214 (2014)

2"FLUKA: a multi-particle transport code" A. Ferrari, P.R. Sala, A. Fasso`, and J. Ranft, CERN-2005-10 (2005), INFN/TC_05/11, SLAC-R-773

${ }^{3}$ Tylka, A.J., Adams, Jr., J.H., Boberg, P.R., Brownstein, B.,Dietrich, W.F., Flueckiger, E.O., Petersen, E.L., Shea, M.A., Smart, D.F., and Smith, E.C., “CREME96: A Revision of the Cosmic Ray Effects on Micro-Electronics Code,” IEEE Trans. Nucl. Sci. Vol. 44, 1997, pp. 2150-2160.

${ }^{4}$ Wilson, J.W., Badavi, F.F., Cucinotta, F.A., Shinn, J.L., Badhwar, G.D., Silberberg, R., Tsao, C.H., Townsend, L.W., and Tripathi, R.K., "HZETRN: Description of a Free-Space Ion and Nucleon Transport and Shielding Computer Program,” NASA Technical Paper 3495, 1995.

${ }^{5}$ Rojdev, K., Koontz, S., Atwell, W., and Boeder, P., "Investigation of HZETRN 2010 as a Tool for Single Event Effect Qualification of Avionics Systems," Space 2014, San Diego, 2014.

${ }^{6}$ Koontz, S., Reddell, B., and Boeder, P., "Calculating Spacecraft Single Event Environment with FLUKA," Radiation Effects Data Workshop, Las Vegas, 2011.

American Institute of Aeronautics and Astronautics 